\title{
ANALISIS EFISIENSI PENGGILINGAN PADI DI SENTRA PRODUKSI PADI (STUDI KASUS DI KECAMATAN KEPANJEN KABUPATEN MALANG)
}

\author{
Joko Gagung S dan Mochamad Fadil \\ Penyuluh Pertanian Di Dinas Pertanian Kabupaten Bondowoso \\ Email :jokojogas@gmail.com
}

\begin{abstract}
ABSTRAK
Penelitian ini bertujuan untuk Mengetahui tingkat efisiensi mesin penggilingan padi di Kecamatan Kepanjen ,Mengetahui tingkat persentase serapan gabah di penggilingan padi di Kecamatan Kepanjen yang berasal dari kecamatan kepanjen dan dari luar kecamatan kepanjen, Mengetahui bulan-bulan operasional penggilingan., Mengetahui adanya kerjasama antara petani, penggilingan, dan Bulog. Metode penelitian ini studi kasus pada penggilingan padi. Sampel di tentukan dengan cara purposisive sampling di 31 (tiga puluh satu) unit penggilingan padi . Responden di masing-masing unit penggilingan padi ditetapkan sesuai dengan orang yang menguasai pada bagian -bagian dalam proses penggilingan padi. Berdasarkan kajian pustaka dan hasil penelitian ini efisiensi penggilingan padi di Kecamatan Kepanjen rata-rata sebesar 1,12 yang berarti efisiens, rata-rata serapan gabah kering giling sebesar $80 \%$ dari kapasitas mesin gilingnya yang berarti belum maksimal, Badan operasional penggilingan padi untuk periode musim panen ke II yaitu 2 bulan (54 hari). Dalam bulan agustus dan september, belum ditemukan adanya kerjasama dengan petani maupun bulog.
\end{abstract}

Kata kunci : Efisiensi dan penggilingan padi.

\begin{abstract}
The purpose of this research is to know the efficiency level of rice milling machine in Kepanjen Subdistrict, to know the percentage rate of paddy uptake in rice milling in Kepanjen Subdistrict coming from Kepanjen Subdistrict and from outside Kepanjen Subdistrict Know the milling operational months. Knowing the existence of cooperation between farmers, milling, and Bulog. This research method is case study on rice milling. The sample was determined by purposive sampling in 31 (thirty one) rice milling units. Respondents in each rice milling unit are set according to the person who controls the parts in the rice mill process. Based on literature review and the results of this study the efficiency of rice milling in Kepanjen Subdistrict an average of 1.12 which means efficiency, the average uptake of unhulled milled grain by $80 \%$ of its milling machine capacity which means not maximal, the operational body of rice milling for the season period the second harvest is 2 months (54 days). In August and September, there has been no cooperation with farmers or bulog.
\end{abstract}

Keywords: Efficiency and rice milling.

\section{PENDAHULUAN}

Kebutuhan pangan yang senantiasa meningkat harus dipenuhi oleh produksi petani. Namun petani sebagai produsen biaya-biaya yang dikeluarkan perlu diganti melalui penerimaan hasil penjualan produksinya. Sedangkan masyarakat sebagai konsumen perlu jaminan ketersediaannya dalam harga yang terjangkau. Untuk itu perlu kebijakan (program) pemerintah melalui lembaga tertentu untuk memerankan fungsi tertentu . Penggilingan padi khususnya di wilayah kepanjen yang merupakan sentra padi di 
kabupaten Malang, sangat potensi untuk membantu program pemerintah meningkatkan serapan gabah kering panen (GKP) yang di proses menjadi beras harus terjamin kelangsungan hidupnya. Peningkatan nilai tambah gabah kering panen menjadi gabah kering giling (nilai marjin ini masih dibebani dengan biaya perontokan, pengeringan, pembersihan, sortasi, penyosohan, grading dan pengemasan jika harus dijual dalam bentuk beras) harus sesuai dengan kapasitas mesin penggilingan yang digunakan, maka perlu penyediaan bahan baku secara memadai. Namun efisienkah Penggilingan jika mengambil bahan baku dari luar wilayah kecamatan tersebut, adanya realita pembelian gabah tidak boleh ke daerah lain, dan bulan panen yang berbeda karena bulan awal tanam yang berbeda.

Hubungan kelembagaan petani , penggilingan dan Bulog masih belum tertata dengan untuk menjalankan fungsinya masing-masing. Dengan demikian persoalannya apakah potensi padi dapat mensupply kebutuhan penggilingan dan atau efisienkah penggilingan jika mengambil bahan baku dari luar wilayah.

Tujuan dalam penelitian ini adalah:

(1) Mengetahui tingkat efisiensi mesin penggilingan padi di Kecamatan Kepanjen,

(2) Mengetahui tingkat persentase serapan gabah di penggilingan padi di Kecamatan Kepanjen yang berasal dari kecamatan kepanjen dan dari luar kecamatan kepanjen, (3) Mengetahui bulan-bulan operasional penggilingan, (4) Mengetahui adanya kerjasama antara petani, penggilingan, dan Bulog.

\section{METODOLOGI}

\section{LokasidanWaktu}

Kegiatan penelitian ini dilaksanakan di Kecamatan Kepanjen Kabupaten Malang pada bulan Agustus - Nopember 2016.

\section{Metodologi Penelitian}

Daerah penelitian di tentukan secara purposive. Metode penelitian ini studi kasus pada penggilingan padi . Sampel di tentukan dengan cara purposisive sampling di 31 (tiga puluh satu) unit penggilingan padi . Responden di masing - masing unit penggilingan padi ditetapkan sesuai dengan orang yang menguasai pada bagian -bagian dalam proses penggilingan padi

\section{Sumber Data}

Data primer diperoleh dari responden yang ditetapkan berjumlah \pm 31 orang dan mengetahui bidang yang ditangani. Responden merupakan pemilik dari penggilingan padi. Data sekunder diperoleh dari beberapa instansi yang terkait

\section{Teknik Pengumpulan Data}

Instrumen untuk mendapatkan data adalah dengan menggunakan perangkat kuisioner. Dan diikuti dengan wawancara untuk pengembangan informasi.

\section{Analisa Data}

a. Efiensi dianalisis dengan menggunakan tabulasi sederhana yaitu tabel rugi laba dengan menghitung BEP proses penggilingan padi

b. Selanjutnya ditetapkan efisien jika kapasitas penggilingannya $=\mathrm{BEP}$ produksi $+\geq 30 \%$ nilai produksi pertahunnya dan $\mathrm{R} / \mathrm{C}$ ratio.

c. Analisis serapan gabah petani dari kecamatan kepanjen dan dari luar kecamatan kepanjen menggunakan statistik sederhana

d. Analisa bulan-bulan operasional penggilingan gabah menggunakan tabulasi yang dideskripsikan.

e. Analisa deskripsi digunakan untuk menjelaskan adanya kerjasama antara petani, penggilingan, dan Bulog.

\section{HASIL DAN PEMBAHASAN}

\section{Keadaan penggiligan padi}

Tahun pendirian penggilingan padi di kecamatan Kepanjen ini berkisar 
dari tahun 1970 sampai dengan tahun 2015. Penggilingan padi yang berdiri di bawah tahun 2000sebanyak 32,3\%; yang berdiri diantara tahun 2000 sampai dengan 2010 sebanyak $37,7 \%$ dan yang berdiri di antara tahun 2011 sampai dengan 2015 sebanyak 29\% dari Seluruhresponden sebanyak 31. Surat surat yang dinyatakan dimiliki oleh beberapa respondenmeliputi surat izin desa, SIUP, SITU,TDP dan NPWP.Jarak pemasok gabah ke RMU berkisar $0,25 \mathrm{~km}$ sampai dengan $2 \mathrm{~km}$, kecuali yangmengambil dari luar kecamatan
Kepanjen sampai menempuh jarak 10, km, $20 \mathrm{~km}, 100 \mathrm{~km}$.Harga gabah kering panen yang dibeli berkisar antara $\mathrm{Rp} 450.000$ sampai denganRp 530.000 per-Kw. Variasi harga penjualan beras mulai $\mathrm{Rp}$ 8500/kg sampai denganRp 9700/ kg, tergantung kondisi beras.

\section{Rata-Rata Penerimaan, Biaya, Keuntungan, BEP dan $\mathrm{R} / \mathrm{C}$ ratio.}

Penggilingan Padi di Kecamatan Kepanjen Tahun 2016 dapat dilihat pada Tabel 1.

Tabel 1: Rata-Rata Penerimaan, Biaya, Keuntungan, BEP dan R/C Ratio Di Penggilingan Padi Kecamatan Kepanjen Tahun 2016

\begin{tabular}{|c|c|c|}
\hline No. & Uraian & Nilai Rata-rata ( Rp) \\
\hline \multirow[t]{6}{*}{ A } & Total nilai beras & 756874354,8 \\
\hline & total nilaimenir & 51112943,55 \\
\hline & Total nilai katul & 14186169,35 \\
\hline & Total nilai dedak & 15590322,58 \\
\hline & Total nilai sekam & 2849258,065 \\
\hline & Total Penerimaan & 840613048,4 \\
\hline \multirow[t]{10}{*}{$\mathrm{B}$} & Total nilaiGKP & 714378709,7 \\
\hline & Totalsolar & 3206870,968 \\
\hline & Nilai oli & 258709,6774 \\
\hline & total nilai karung/musim & 5662741,935 \\
\hline & Nilai plastik packing/musim & 481619,3548 \\
\hline & Biaya per bulan bayar listrik & 93064,51613 \\
\hline & Biaya TK Jemur & 9224193,548 \\
\hline & Biaya TK Giling & 3891935,484 \\
\hline & Biaya TK Packing & 5527469,726 \\
\hline & Total Biaya Variabel & 742725314,9 \\
\hline $\mathrm{C}$ & Keuntungan Kotor & 97887733,5 \\
\hline \multirow[t]{8}{*}{$\mathrm{D}$} & Nilai sewa per- musim & 2650322,581 \\
\hline & Penyusutanbangunan/musim & 144086,0106 \\
\hline & Penyusutan lantai jemur/musim & 194854,0484 \\
\hline & Penyusutan mesin giling/musim & 473225,7903 \\
\hline & Penyusutan alat jahit/musin & 16880,17097 \\
\hline & Penyusutan seller/musim & 13010,74516 \\
\hline & SusutAlat lain & 17204,29677 \\
\hline & Total Biaya Tetap & 3509583,643 \\
\hline $\mathrm{E}$ & Total Biaya & 746234898,5 \\
\hline $\mathrm{F}$ & Keuntungan Bersih & 94378149,86 \\
\hline $\mathrm{G}$ & Breack Event Point & 0,035853151 \\
\hline $\mathrm{H}$ & R/C Ratio & 1,126472442 \\
\hline
\end{tabular}


Dari tabel 1 tersebut , rata-rata usaha penggilingan padi di kecamatan Kepanjen masih dapat dikategorikan efisien dengan nilai $\mathrm{R} / \mathrm{C}$ ratio sebesar 1,12. Hal ini disebabkan penerimaan lebih besar dari pada total biayanya yaitu Rp 840613048,4 lebih besar dari pada Rp 746234898,5. Walaupun demikian dari 31 responden, usaha penggilingan responden yang $\mathrm{R} / \mathrm{C}$ rationya lebih besar satu $(\mathrm{R} / \mathrm{C}$ ratio 1,16 sebanyak 19 responden $(61, \%)$ dan yang $\mathrm{R} / \mathrm{C}$ rationya lebih kecil satu $(0,89)$ sebanyak 12 responden $(38,71 \%)$. Hal ini terjadi karena usaha responden yang $\mathrm{R} / \mathrm{C}$ rationya lebih besar satu, biayanya di atas nilai BEP nya Sedang, usaha responden yang R/C rationya lebih kecil satu , biayanya di bawah nilai BEP nya. Sebagaimana nilai BEP usaha penggilingan padi yaitu sebesar 0,0358 empat persen) dari nilai penjualannya ( $4 \% \quad \mathrm{X}$ Rp $840613048,4=\operatorname{Rp}$ 33624521,94 ). Dari Tabel 1 tersebut dapat dilihat bahwa total biaya yang dikeluarkan di atas biaya BEP nya, sehingga dapat menguntungkan. Total biaya yang dikeluarkan sebesar $\mathrm{Rp}$ 746234898,5 dan keuntungannya sebesar Rp 94378149,86. Rata-rata penerimaan dan pembiayaan tersebut pada tabel 1 diperoleh dari penggunanaan sarana dan prasarana sebagaimana pada tabel 2 .

Tabel 2: Rata-Rata Kebutuhan Sarana Prasarana Dalam Proses Penggilingan Padi selama rata-rata 54 hari (masa giling) di Kecamatan Kepanjen Tahun 2016

\begin{tabular}{|c|l|l|}
\hline $\begin{array}{c}\text { No } \\
\cdot\end{array}$ & \multicolumn{1}{|c|}{ Uraian } & $\begin{array}{c}\text { Rata-Rata Jumlah per } \\
\text { masa giling }\end{array}$ \\
\hline 1 & jemur GKP $(\mathrm{kw})$ & 2013,085161 \\
\hline 2 & Susut (Kw) & 318,0674555 \\
\hline 3 & Giling GKG(kw) & 1722,512903 \\
\hline 4 & Kapasitas giling(kw) & 2402,129032 \\
\hline 5 & Giling satu kali musim panen (hari) & 54 \\
\hline 6 & Hasil giling beras(kw) & 1160,477419 \\
\hline 7 & Hasil giling menir(kw) & 145,0596774 \\
\hline 8 & Hasil giling katul(kw) & 75,43103226 \\
\hline 9 & Hasil giling Dedak(kw) & 377,1551613 \\
\hline 10 & Hasil giling sekam(kw) & 150,8620645 \\
\hline 11 & luas tanah yang digunakan (m2) & 1060,129032 \\
\hline 12 & Luas bangunan RMU (m2) & 65,83870968 \\
\hline 13 & Luas Lantai Jemur (m2) & 216,5806452 \\
\hline 14 & Bahan bakar (liter) & 663,6774194 \\
\hline 15 & Oli pelumas (liter) & 6 \\
\hline 16 & kebutuhan karung ( Zak ) & 3775,16129 \\
\hline 17 & Kebutuhan Plastik Packing (lembar) & 321,0795699 \\
\hline 18 & Tenaga Kerja jemur (orang) & 207,2903226 \\
\hline 19 & Tenaga Kerja giling (orang) & 78,38709677 \\
\hline 20 & Tenaga Kerja packing (orang) & 144,5806452 \\
\hline
\end{tabular}

Pada tabel 2 tersebut, rata-rata masa giling selama 54 hari. Gabah kering panen yang dibeli dari petani rata-rata sebanyak 2013,085161 Kw, dan mengalami penyusutan sebanyak $318,0674555 \mathrm{Kw}$ ( $\%$ ). Sehingga gabah kering giling yang digiling sebanyak 1722,512903 Kw. Sedangkan rata-rata kapasitas gilingnya 331 | Jurnal Agriekstensia Vol. 16 No. 2 Desember 2017 sebesar 2402,129032 Kw. Lebih kecil gabah yang digiling karena keterbatasan modal untuk membeli gabah secara sekaligus pada saat musim panen. Sedangkan hasil giling yang diperoleh berupa beras, menir, katul , dedak, dan sekam yang masing-masing sebanyak $1160,477419 \mathrm{Kw}, \quad 145,0596774 \mathrm{Kw}$, 
75,43103226 Kw, 377,1551613 Kw, $150,8620645 \mathrm{Kw}$. Besar kecil kondisi menir, katul, dedak dan sekam tergantung kekeringan gabah, proses yang dilalui dalam penggilingan gabah tersebut atau kelengkapan alat yang digunakan dalam proses penggilingan. Dan dalam operasionalnya penggilingan tersebut menggunakan tanah rata-rata seluas $1060,129032 \mathrm{~m} 2$ yang digunakan untuk bangunan rata-rata seluas $65,83870968 \mathrm{~m} 2$, dan untuk lantai jemur seluas rata-rata 216,5806452 m2, serta selebihnya untuk lain-lain. Adapun bahan bakar yang digunakan rata-rata sebesar 663,6774194 liter dan oli pelumas sebesar enam liter. Sedangkan karung beras yang digunakan rata-rata 3775 zak ukuran $25 \mathrm{~kg}$, dan kantongan plastik berukuran lima dan sepuluh kilogram. Dan rata-rata total tenaga kerja yang digunakan mulai proses penjemuran, penggilingan dan pengepakan sebanyak 430,26 orang yang bekerja selama tujuh jam.

Jika responden digolongkan kedalam usaha penggilingan yang $\mathrm{R} / \mathrm{C}$ rationya lebih besar satu dan yang lebih kecil satu maka dapat dilihat sebagaimana tabel 3 .

Tabel 3: Rerata Penerimaan dan Biaya Berdasarkan Usaha yang $\mathrm{R} / \mathrm{C}$ rationya lebih besar satu dan yang lebih kecil satu

\begin{tabular}{|l|l|c|c|}
\hline No. & Uraian & $\begin{array}{l}\text { Usaha } \\
\text { Penggilingan Yang } \\
\text { R/C ratio }>1\end{array}$ & $\begin{array}{l}\text { UsahaPenggilingan } \\
\text { Yang R/C rationya } \\
<1\end{array}$ \\
\hline 1. & Penerimaan ( Rp) & 1161346487 & 332785104,2 \\
\hline 2. & Biaya Tetap ( Rp ) & 3804320,717 & 439074,0676 \\
\hline 3. & Biaya Variabel ( Rp ) & 804877704,6 & 368408614,6 \\
\hline 4. & Efisiensi Usaha (Rp) & 1,161702064 & 0,88850312 \\
\hline 5. & Lama Penggilingan (Hari) & 51,78947368 & 57,5 \\
\hline 6. & $\begin{array}{l}\text { Jumlah Gabah Kering Giling Selama } \\
\text { masa Giling (Kw) }\end{array}$ & 2125,276454 & 1002,177083 \\
\hline 7. & $\begin{array}{l}\text { Kapasitas GKG Selama Masa Giling ( } \\
\text { Kw }\end{array}$ & 2643,98892 & 1241,041667 \\
\hline
\end{tabular}

Dari tabel 3 tersebut dapat dijelaskan bahwa jumlah responden yang rata-rata nilai efisiensi usaha penggilingan padinya sebesar 1,16 sebanyak $61,29 \%$ dan jumlah responden yang rata-rata nilai efisiensi usaha penggilingan padinya sebesar 0,89 sebanyak 38,71\%.Dan apabila diuji secara statistik perbedaan nilai efisiensi tersebut tidak berbeda nyata. Dan jika penerimaannya usaha penggilingan yang efisiensinya sebesar 0,89 dibandingkan dengan nilai rata-rata BEP seluruh responden selisihnya sebesar $\mathrm{Rp}$ 299160582,26 lebih besar dari pada BEPnya. Sehingga sebenarnya efisien dilihat dari BEP, namun dilihat dari $\mathrm{R} / \mathrm{C}$ rationya lebih kecil 1 . Hal ini diduga disebabkan jumlah hari operasional di atas jumlah hari rata-rata responden, sehingga menyebabkan tingginya biaya variabel yang tidak diikuti dengan pertambahan penerimaannya yang sebanding. Karena Biaya tetapnya lebih kecil dibandingkan dengan biaya tetap yang $\mathrm{R} / \mathrm{C}$ rationya lebih besar satu.

\section{Adapun rata-rata gabah kering giling yang dapat diserap}

Pada penggilingan yang $\mathrm{R} / \mathrm{C}$ rationya lebih kecil satu sebesar 1002,18 Kw ( $80,75 \%)$ GKG dari rata-rata kapasitas mesin giling sebesar 1241,04 Kw. Dan rata-rata gabah kering giling yang dapat diserap oleh penggilingan yang $\mathrm{R} / \mathrm{C}$ rationya lebih besar satu sebesar 
$2125,28 \mathrm{Kw}(80,38 \%)$ GKG dari rata-rata kapasitas mesin giling sebesar 2643,99 Kw GKG. 26\% responden memenuhi serapan gabahnya dari dalam sebesar 52\%dan dari luar kecamatan Kepanjen sebesar 48\%, sedangkan $74 \%$ responden memenuhi serapan gabahnya dari dalam kecamatan Kepanjen saja, hal dapat dimaklumi karena adanya keterbatasan modal. Sedangkan untuk perioda penggilingan tersebut pada musim panen tersebut dilakukan pada bulan-bulan Agustus dan September. Adapun adanya kerjasama penggilingan dengan petani dan atau penebas hanya dilakukan oleh 22,6\% responden. Kerjasama dengan Bulog hanya dilakukan oleh $6,5 \%$ responden. Selebihnya tidak bekerjasama, karena tidak memenuhi kuotanya, sudah punya pelanggan dan harga yang kurang bersaing.

\section{KESIMPULAN DAN SARAN}

\section{Kesimpulan}

Efisiensi penggilingan padi di kecamatan Kepanjen rata-rata sebesar 1,12 yang berarti efisien. Rata-rata serapan gabah kering giling sebesar $80 \%$ dari kapasitas mesin gilingnya yang berarti belum maksimal. Bulan operasional penggilingan padi untuk perioda musim panen ke II, yaitu 2 bulan ( 54 hari), dalam bulan Agustus dan September. d). Belum ditemukan adanya kerjasama dengan petani maupun Bulog.

\section{Saran}

Masih diperlukan peningkatan efisiensinya melalui pengelolaan hasil giling dan penyempurnaan penggilingan. Memaksimalkan proses penggilingan melalui dukungan modal untuk penyediaan bahan giling sesuai kapasitas mesin dan waktu yang tersedia sampai musim panen berikutnya. Memerlukan pembinaan kelompok tani agar dapat bekerjasama simbiosis dengan penggilingan padi dan kerjasama Bulog dengan penggilingan padi.

\section{DAFTAR PUSTAKA}

Anang B dan Sawit, 1999. Kebijakan Beras dan Pangan Nasional Pelajaran dari Orde Baru dan Era Reformasi. Jakarta, IPB Press.

Dawam Raharjo, 1984, Transformasi Pertanian, Industrialisasi, UI Press, Jakarta.

Delima Hasri Azahari, Volume 1. No.1. 2003. Dirjen Bina Pengolahan dan Pemasaaran Hasil Pertanian.

Downey, W.D. dan Erickson ,SP, 1989, Agribusiness Management, Mc. Grew Hill Inc, New York.

Hernanto Fadholi,1995, Ilmu Usahatani, Penebar Swadaya, Anggota

Kadarsan H.W., 1992, Keuangan Pertanian Dan Pembiayaan Perusahaan Agribisnis, Gramedia Pustaka Utama, Jakarta.

Mubyarto, 1977, Pengantar Ekonomi Pertanian, LP3ES, Yogyakarta.

Nasution A. H., dan Imam Baihaqi, 2007, Simulasi Bisnis, Andi Offset, Yogyakarta.

Pusat Penelitian dan Pengembangan Sosial Ekonomi Pertanian, 2005. Ratnawati, Dewi Adhi. 2001. Analisis Pendapatan Usahatani dan Sistem Pemasaran beras di Desa Alamendah, Kecamatan Ciwidey, Kabupaten bandung, Jawa Barat. Jurusan Ilmu-Ilmu Sosial Ekonomi Pertanian, Fakultas Pertanian Institut Pertanian Bogor.

Sedarmayanti dan Syarifudin Hidayat, 2011, Metodologi Penelitian, Mandar Maju, Bandung.

Soekartawi, Soeharjo, Dillon, Brian Hardaker, 1986, Ilmu Usahatani dan Penelitian Untuk 
Pengembangan Petani Kecil, UI Press, Jakarta.

Soekartawi dkk. 1986. Ilmu Usahatani dan Penelitian untuk Pengembangan Petani Kecil. Universitas Indonesia. Jakarta.

, Prinsip Dasar

Ekonomi Pertanian : Teori dan Aplikasinya, Rajawali, Malang.
Sugiyono.2012. Metode Penelitian Kuantitatif, Kualitatif dan R\&D. CV. Alfabeta Bandung.

The Liang Die, 1982, Cara Bekerja efisien, Liberty, Yogyakarta.

Tohir A.Kaslan, 1982. Usahatani Indonesia 2. Penerbit Rineka Cipta Jakarta 